\title{
Efficient Train Operation for Sustainable Freight Transportation: Optimizing Frequency with Fleet Size Constraints
}

\author{
Dong-Kyu Kim*, Minyoung Park**
}

\begin{abstract}
Sustainable transport has become a new paradigm offering efficient, equitable, and pro-environment transport services. Many intermodal freight systems, especially those for port-to-rail networks, consist of multiple routes starting from and ending at the same port in order to exploit economies of scale. It is of interest to railway operators, therefore, to improve the efficiency of the system by finding the optimal fleet size (the number of cars assigned to a route) and frequency for each route. This paper proposes a model which determines the optimal frequency of each route under the total fleet size constraint for the one-to-many distribution. Trains carry items from one port to their destinations on their predetermined routes. This paper focuses on situations in which items from one port are transported to many destinations via railroads. The tradeoffs between transportation and inventory costs determine optimal frequency under the total fleet size and capacity constraints. The optimal frequency and fleet size of each route are calculated and then updated at the end of each step of the model. The model that we have developed in this paper is validated by port-to-rail freight data from actual shipments in Korea. The results of the analysis show that the proposed model can provide a more reliable and realistic representation of the real one-to-many distribution than the other alternatives which are commonly used. This study not only forms the theoretical basis of an effective and rational freight operation, but it also contributes to the assessment of the existing and planned logistics systems.
\end{abstract}

Keywords: sustainable transportation, efficiency, fleet size constraint, frequency optimization, freight train

Submisson Date : 02/18/2012 Revision Date : 03/05/2012 Acceptance Date : 03/05/2012

${ }^{*}$ BK21 Professor, Department of Civil and Environmental Engineering, Seoul National University, Korea E-mail: kimdk95@snu.ac.kr

** Corresponding author, Professor, Graduate School of Logistics, Inha University, Korea E-mail: mypark@inha.ac.kr 


\section{Introduction}

Sustainable transport has become a new paradigm which offers efficient, equitable, and pro-environment transport services. The railroad industry has been facing fierce competition and decreasing market share in the area of freight transportation. In this context, a more rational and efficient operation of the available resources is required. Many studies related to train operation have been conducted in a variety of different areas such as facility operation, standardization, pricing strategy, transportation policy and planning. Assad (1980) has determined the most efficient train types and railway routes in order to minimize the total cost. Eilon et al. (1971) formulated a model to determine optimal depot locations, freight scheduling, loading and fleet size. Crainic et al. (1984) investigated the three planning level stages (strategic, tactical and operational) and determined the best service frequency and train make-up.

Hall (1993) classified the local area freight networks (LANs) topologies and showed how the optimal topology for a common carrier depends on the demand characteristics. When formulating train-scheduling and container allocating problems, Newman and Yano (2000) considered a fixed charge for each train, variable transportation and handling costs for each container and calculated yard storage costs as operating costs.

Choong et al. (2002) studied empty container management in order to minimize the summation of moving costs between locations, holding at pools and bringing from outside of the system. Groothedde et al. (2005) formulated economies of scale stemming from not only the transport cost function for inter-hub flows which was suggested by O'Kelly and Bryan (1998), but also handling and transshipment costs from hubs. Logistic costs of demand which are transported via hubs have comprised the shipment time costs, transport time costs, handling costs, inventory costs, and planning and control costs as well as transport costs.

Janic (2007) has recently formulated the internal and external cost functions of intermodal freight transport networks. Transport, time, handling, and external costs have been formulated based on Daganzo (2005) and have been compared with the road freight transport networks. The other recently published studies which we feel are related to this topic include (Constantin et al. (1995), van Oudheusden and Zhu (1995), Marín and Salmerón (1996), Furth and Rahbee (2000), Saka (2001), dell'Olio at al. (2006), and Francis (2006)) are summarized in Table 1.

This paper focuses on physical distribution problems which occur when items at a single origin need to be taken to multiple destinations, especially port-to-rail networks. Trains start from and end at one port in order to exploit economies of scale. When a train 
returns to the port after its trip, it can also be reassigned to another route. The optimal fleet size (i.e., the number of cars assigned to a route) and the frequency of each route can be changed according to the forecasted demand variation under the total fleet size constraint. The initial solution of the frequency of each route is calculated through EOQ (Economic Order Quantity) trade-offs and is then updated in order to satisfy the total fleet size constraints. The model in this paper is evaluated using real-world data from the Korea Transport DataBase (KTDB) (http://www.ktdb.go.kr).

The remainder of this paper is organized as follows. In the next section, we discuss the problem definition, cost function and model formulation. Next, the analytical approach and solution algorithm are discussed. Then, we present empirical studies for evaluation of the proposed model. Lastly, our summary and discussion are presented.

Table 1.

Existing pertinent literature

\begin{tabular}{|c|c|c|c|}
\hline Literature & Decision Variables & $\begin{array}{c}\text { Objective Function } \\
\text { (Components) } \\
\end{array}$ & $\begin{array}{c}\text { Mode } \\
\text { (Network) } \\
\end{array}$ \\
\hline $\begin{array}{l}\text { Constantin and } \\
\text { Florian (1995) }\end{array}$ & $\begin{array}{l}\text { Higher level } \\
\text {-Line frequencies } \\
\text { Lower level } \\
\text {-Transit volume } \\
\text {-Waiting time }\end{array}$ & $\begin{array}{l}\text {-Min. [Travel and waiting time] } \\
\text {-Constraint: Total expenditure (the } \\
\text { number of transit vehicles) }\end{array}$ & $\begin{array}{l}\text {-Rail } \\
\text { (Toy network in } \\
\text { EMME/2) }\end{array}$ \\
\hline $\begin{array}{l}\text { van } \\
\text { Oudheusden } \\
\text { and Zhu (1995) }\end{array}$ & -Frequency scheduling & $\begin{array}{l}\text {-Min. [Difference of frequencies] } \\
\text { (Required - scheduled } \\
\text { frequencies) }\end{array}$ & $\begin{array}{l}\text {-Bus } \\
\text { (Bangkok) }\end{array}$ \\
\hline $\begin{array}{l}\text { Marín and } \\
\text { Salmerón } \\
(1996)\end{array}$ & $\begin{array}{l}\text {-Frequency } \\
\text {-Route of trains }\end{array}$ & $\begin{array}{l}\text {-Min. [Total costs] } \\
\text { (Routing, frequency, investment) }\end{array}$ & $\begin{array}{l}\text {-Rail } \\
\text { (Toy network) }\end{array}$ \\
\hline $\begin{array}{l}\text { Furth and } \\
\text { Rahbee (2000) }\end{array}$ & -Stop spacing & $\begin{array}{l}\text {-Min. [Total costs] } \\
\text { (Operating cost, riding/walking } \\
\text { time) }\end{array}$ & $\begin{array}{l}\text {-Bus } \\
\text { (Boston) }\end{array}$ \\
\hline Saka (2001) & -Stop spacing & $\begin{array}{l}\text {-Min. [Total travel times (Fleet } \\
\text { size)] } \\
\text { (Acc/dec time, dwell time, signal } \\
\text { delay, moving time, miscellaneous } \\
\text { delay) }\end{array}$ & $\begin{array}{l}\text {-Bus } \\
\text { (Baltimore) }\end{array}$ \\
\hline $\begin{array}{l}\text { dell'Olio, } \\
\text { Moura et al. } \\
(2006)\end{array}$ & $\begin{array}{l}\text { Upper level } \\
\text {-Frequency } \\
\text { Lower level } \\
\text {-Stop spacing }\end{array}$ & $\begin{array}{l}\text {-Min. [Total costs] } \\
\text { (Upper level: travel, company, } \\
\text { construction cost) } \\
\text { (Lower level: journey cost) }\end{array}$ & $\begin{array}{l}\text {-Bus } \\
\text { (Santander) }\end{array}$ \\
\hline $\begin{array}{l}\text { Francis, } \\
\text { Smilowitz et al. } \\
(2006)\end{array}$ & $\begin{array}{l}\text {-Visited number of nodes } \\
\text {-Traversed number of } \\
\text { links }\end{array}$ & $\begin{array}{l}\text {-Min. [Costs - Benefits] } \\
\text { (Travel, stopping time) }\end{array}$ & $\begin{array}{l}\text {-General } \\
\text { (Toy network) }\end{array}$ \\
\hline
\end{tabular}




\section{Model Development}

\subsection{Problem Definition}

We define our problem as follows: Consider a situation in which $S$ cars can be assigned to $R$ predetermined routes. We want to determine the optimal fleet size $s_{r}^{*}$ (the number of cars to be assigned to a route $r$ ) and the frequency $f_{r}^{*}$ of each route $r$ $(r=1,2, \cdots, R)$. Trains start from and arrive at a port and stop at $L_{r}$ stations while moving along the route $r$. The definition of our problem is illustrated in Figure 1.

The assumption of fixed routes is not strong since the routes cannot be changed in the short run due to high construction costs. Each train must stop at all stations on its route and the time and cost required for loading and unloading are assumed to be independent of the amount of cargo. The amount of items varies depending on the destinations and time periods while it is independent of the decision variables of the problem, which means that the amounts are inelastic to changes in waiting time. In addition, all demands must be carried out within the given time slots and there is therefore no cumulative excess demand. Each train can be reassigned to another route after finishing its trip in order to adapt to demand variation. Based on the assumptions mentioned above, we want to determine the optimal fleet size and frequency of each route under the total fleet size and capacity constraints. We can refine our problem definition as follows.

Objective: Minimize total costs which consist of transportation costs, stopping costs and inventory costs

Given: $\quad$ All served routes

Demand from a port to all destinations

Time value of an item

Decision: Frequency and fleet size of each route

Constraints: Total fleet size, which affects the maximum frequency of each route

Maximum train capacity, which determines the minimum frequency of each route 


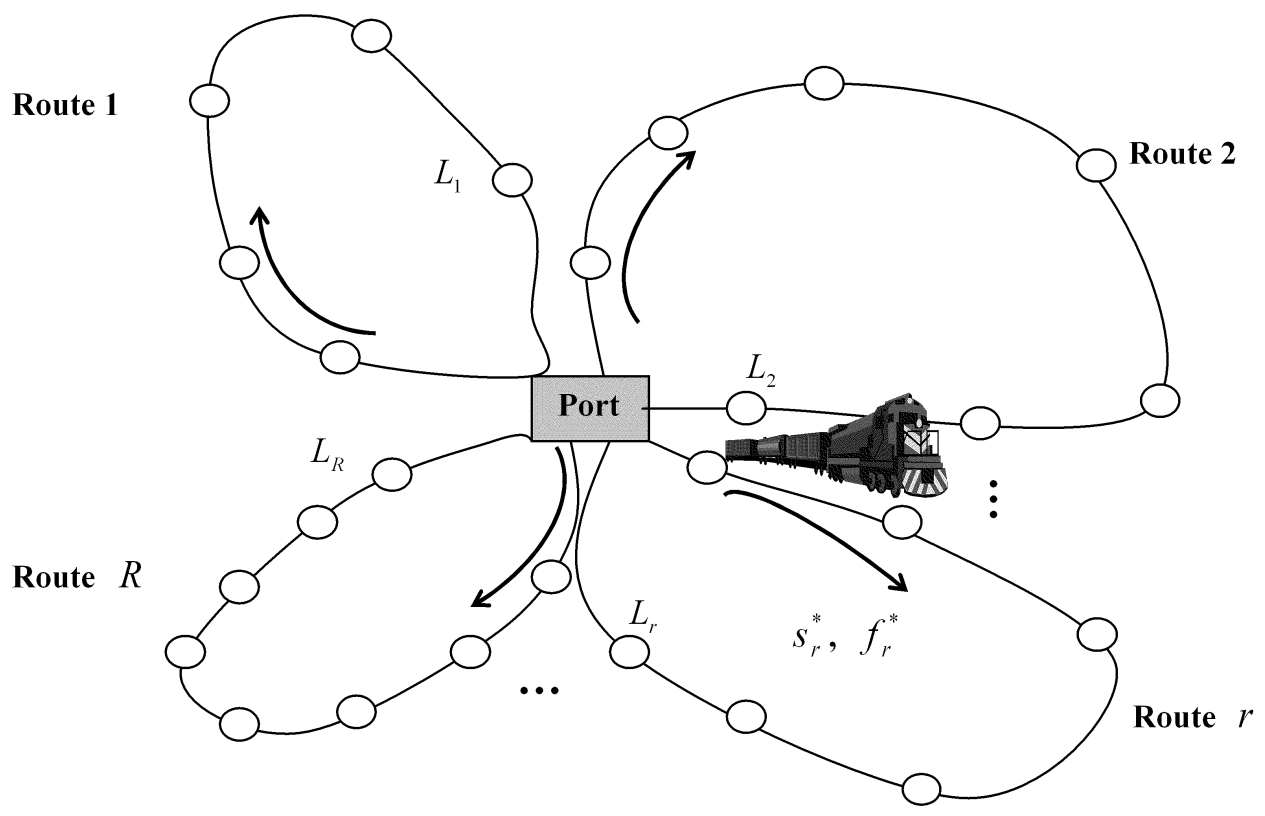

Figure 1.

Problem definition

\subsection{Cost Functions}

The general classification of logistics costs has been developed by many scholars, depending on the objectives of their research. The most important issue in cost classification is "that in the final analysis all costs should be included and none double counted" (Daganzo, 2005). In this study, the total cost of each route consists of four components; transportation costs, stationary and pipeline inventory costs and stopping costs. The notations used in this paper are as follows.

$C_{r}=$ cost of a route $r$

$C_{r}^{T R}=$ transportation cost of a route $r$

$C_{r}^{S T}=$ stopping cost of a route $r$

$C_{r}^{S I}=$ stationary inventory cost of a route $r$

$C_{r}^{P I}=$ pipeline inventory cost a route $r$

$c^{t r}=$ unit transportation cost per length-frequency

$c^{s t}=$ unit stopping cost per stop

$t^{s t}=$ unit stopping time per stop 
$Q_{r}=$ total demand of a route $r$

$D_{r}=$ total distance of a route $r$

$L_{r}=$ the number of stations on a route $r$

$\delta_{r}^{i}=$ journey distance of an item $i$ shipped along a route $r$

$l_{r}^{i}=$ the number of stops traversed by an item $i$ shipped along a route $r$

$f_{r}=$ the frequency that a route is traveled $r$

$\left(f_{r}\right)_{u}=$ optimal frequency of a route $r$ in an unconstrained condition

$f_{r}^{\max }=$ upper limit of frequency of a route $r$

$f_{r}^{\mathrm{min}}=$ lower limit of frequency of a route $r$

$f_{r}^{*}=$ optimal frequency of a route $r$ in a constrained condition

$k_{r}^{\max }=$ maximum capacity of the trains which move along a route $r$

$v_{r}=$ velocity of a train which moves along a route $r$

$t p=$ time horizon of interest

$t v=$ time value of an item

$C_{I}=$ criterion for the integral constraint of frequency

$S=$ the number of trains in a fleet (total fleet size)

$s_{r}^{*}=$ optimal fleet size of a route $r$

Transportation costs or variable costs stem from train movements and have been developed in various forms, in accordance with their particular objectives and applications. We express transportation costs as a function of the frequency and distance of each route as presented by Daganzo (2005) and Zanic (2007).

$$
C_{r}^{T R}=t p \cdot c^{t r} \cdot D_{r} \cdot f_{r}
$$

Stopping costs consist of handling costs and time spent, which occur when trains stop at the scheduled stations. As mentioned above, the handling costs at stations are assumed to be independent of the amount of items which are loaded and unloaded. It should also be noted that time spent is not related to the facilities or to the trains, but to the time it takes to move items. The stopping cost of route $r$ can therefore be written as follows.

$$
C_{r}^{S T}=t p \cdot\left(c^{s t} \cdot f_{r} \cdot L_{r}+t^{s t} \cdot t v \cdot \sum_{i=1}^{Q r} l_{r}^{i}\right)
$$

The two terms in the blanket represent handling costs and time spent during stops, respectively. 
Stationary inventory costs indicate time which is spent waiting and are usually formulated as a function of the headway of shipment trains. The frequency of trains is a reciprocal of the headway, and stationary inventory costs can therefore also be formulated as a function of frequency. Transportation costs increase but stationary inventory costs decrease with an increase in frequency. Stationary costs can therefore be expressed as a function of the following frequency.

$C_{r}^{S I}=\frac{t p \cdot t v}{2 f_{r}} \cdot Q_{r}$

Pipeline inventory costs are the travel time costs of shipped items. Pipeline inventory costs can be calculated by dividing the summation of the journey distance of the items shipped along a route by the velocity of the train and thus can be formulated as Equation [4].

$C_{r}^{P I}=\frac{t p \cdot t v}{v_{r}} \cdot \sum_{i=1}^{Q r} \delta_{r}^{i}$

As mentioned above, the total cost of a route $\gamma, C_{r}$ can be expressed as Equation [5]. In this equation, $C_{r}$ is influenced by the properties of network $\left(D_{r}\right.$ and $\left.L_{r}\right)$, demand $\left(t v^{i}\right.$, $Q_{r}$, and $\left.l_{r}^{i}\right)$,and the operation $\left(f_{r}\right.$ and $\left.v_{r}\right)$ of each route.

$$
\begin{aligned}
C_{r} & =C_{r}^{T R}+C_{r}^{S T}+C_{r}^{S I}+C_{r}^{P I} \\
& =t p \cdot c^{t r} \cdot D_{r} \cdot f_{r}+t p \cdot\left(c^{s t} \cdot f_{r} \cdot L_{r}+t^{s t} \cdot t v \cdot \sum_{i=1}^{Q r} l_{r}^{i}\right)+\frac{t p \cdot t v}{2 f_{r}} \cdot Q_{r}+\frac{t p \cdot t v}{v_{r}} \cdot \sum_{i=1}^{Q r} \delta_{r}^{i}
\end{aligned}
$$

Figure 2 illustrates the relationship between several elements and the cost components of routes $r, C_{r}$. The cost components - transportation, stopping, pipeline and stationary inventory - are influenced by two or more elements. The decision variable in this study is the number of the frequency of each route $r, f_{r}$, which is related to the operation of the train. Figure 3 shows an example of the transportation procedure of an item $i$ along the route to its destination. The item starts from a port and travels to its destination along the given route. 


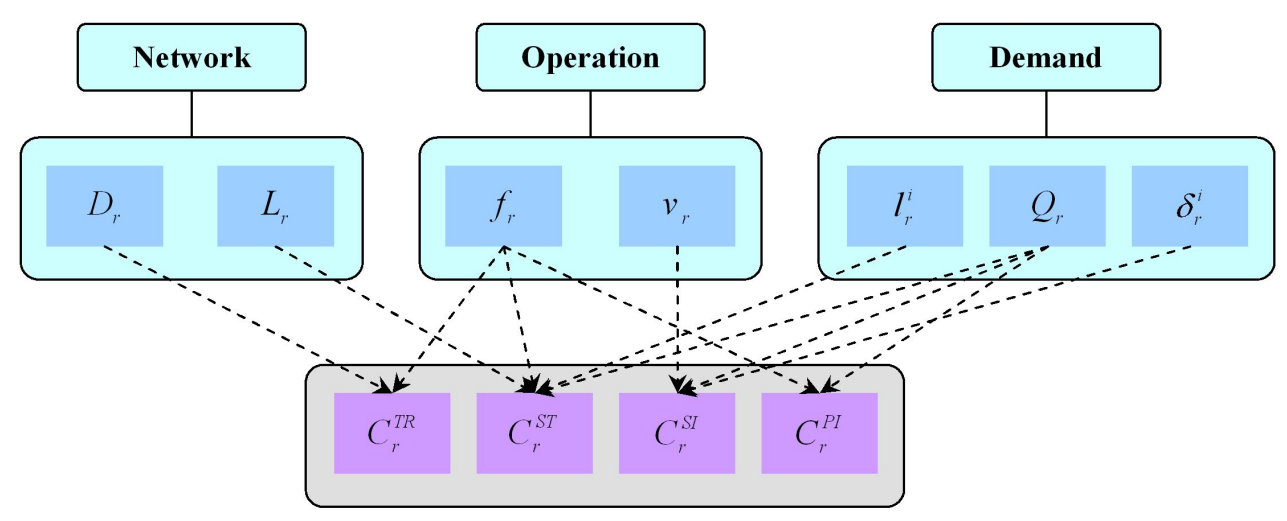

Figure 2.

Relationship components included in cost $C_{r}$

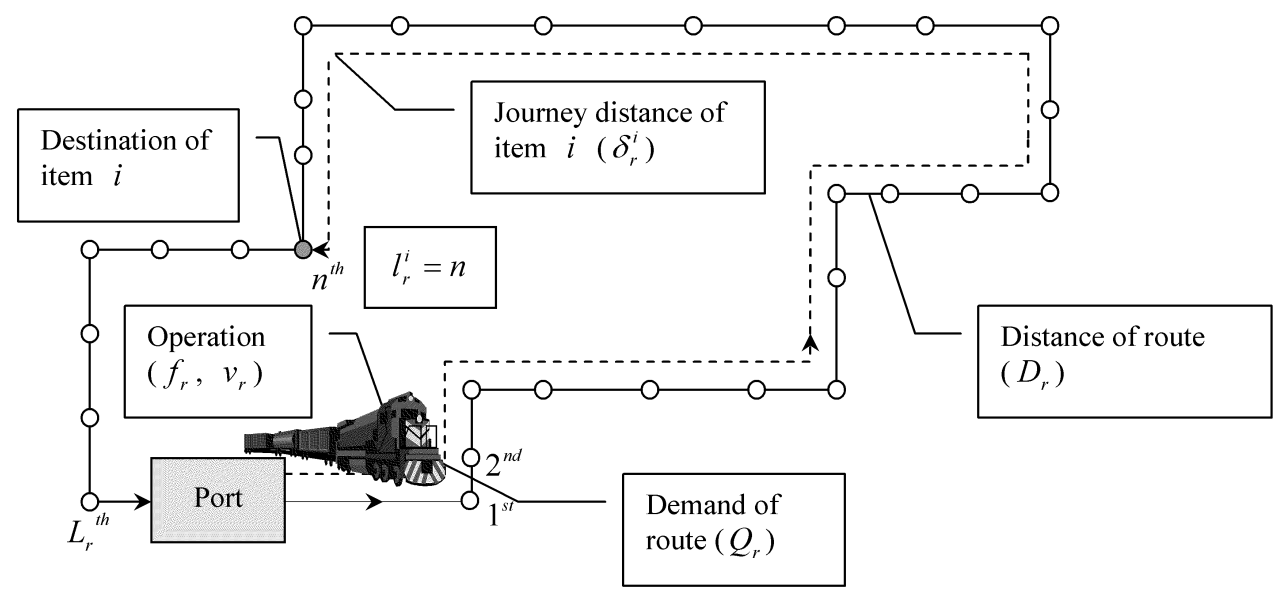

Figure 3.

Transportation procedure of an item $i$ along route $r$

\section{Solution}

\subsection{Optimal Frequency and Minimum Cost in an Unconstrained Condition}

In Equation [5], the handling costs during stops and the pipeline inventory costs are independent of our decision variable, $f_{r}$. We can arrange Equation [5] according to the descending powers of $f_{r}$ as follows. 
$C_{r}=t p \cdot\left\{\left(c^{t r} \cdot D_{r}+c^{s t} \cdot L_{r}\right) \cdot f_{r}+\frac{t v}{2 f_{r}} Q_{r}\right\}+A_{r}$

where,

$A_{r}=t p \cdot t v \cdot\left(t^{s t} \cdot \sum_{i=1}^{Q r} l_{r}^{i}+\frac{1}{v_{r}} \cdot \sum_{i=1}^{Q_{r}} \delta_{r}^{i}\right)$

If we do not consider the integral constraint and the maximum and minimum constraints of our decision variable, $f_{r}$, we can apply the Economic Order Quantity (EOQ) trade-off to Equation [6] (see Daganzo (2005), and Blumenfeld et al. (1985)) and then directly calculate the optimal frequency and minimum cost of each route in an unconstrained condition as in Equations [7] and [8], respectively.

$$
\begin{aligned}
& \left(f_{r}\right)_{u}=\sqrt{\frac{t v \cdot Q_{r}}{2\left(c^{t r} \cdot D_{r}+c^{s t} \cdot L_{r}\right)}} \\
& \left(C_{r}\right)_{u}=t p \cdot\left\{\left(c^{t r} \cdot D_{r}+c^{s t} \cdot L_{r}\right) \cdot f_{r}+\frac{t v}{2 f_{r}} \cdot Q_{r}\right\}+A_{r} \geq t p \cdot Q_{r} \sqrt{\frac{2 t v \cdot\left(c^{t r} \cdot D_{r} \cdot+c^{s t} \cdot L_{r}\right)}{Q_{r}}}+A_{r}
\end{aligned}
$$

As shown in Equation [7], the optimal frequency of each route in an unconstrained condition is proportional to the square root of its demand divided by the stopping and transportation costs per frequency, $\sqrt{Q_{r} /\left(c^{t r} \cdot D_{r}+c^{s t} \cdot L\right)}$. This ratio can also be interpreted as a reciprocal of the "unit frequency cost" of an item along route $r$. The optimal frequency of a route therefore decreases as unit frequency cost increases. In Equation [8], the minimum cost in an unconstrained condition is proportional to the square root of the following elements; stopping and transportation costs per frequency and time value and demand of the items shipped along route $r$. It is reasonable to assume that the unit transportation cost and the stopping cost are constant since we consider the situation in which items are shipped by train. The optimal frequencies of routes along which items with the same time value and average journey distance are shipped, therefore, will have identical results.

Figure 4 shows the change in cost per item of a route $r, C_{r} / Q_{r}$, according to its frequency. Each solid line indicates a set of points with the same unit frequency cost and the dots represent the minimum cost per item and the optimal frequency at each condition. As unit frequency cost increases, the minimum cost per item increases while the optimal frequency decreases. Thus, the efficiency of transport systems can be improved by assigning more trains to routes with larger demand and lower costs;

Figure 5 shows the change in the optimal frequency and the minimum cost of a 
passenger according to the traffic density. As mentioned above, as traffic density increases, the optimal frequency and minimum cost increases and decreases, respectively, but the rates of both decrease. The operator can thus determine whether to increase or decrease the frequency and fleet size of each route based on traffic density.

\subsection{Integral and Maximum/Minimum Constraints on Frequencies}

Let us define the following symbols in order to present the constraints on frequencies.

$\{\lfloor A\rfloor=$ the maximum integer that is equal to or smaller than $A$

$\{\lceil A\rceil=$ the minimum integer that is equal to or larger than $A$

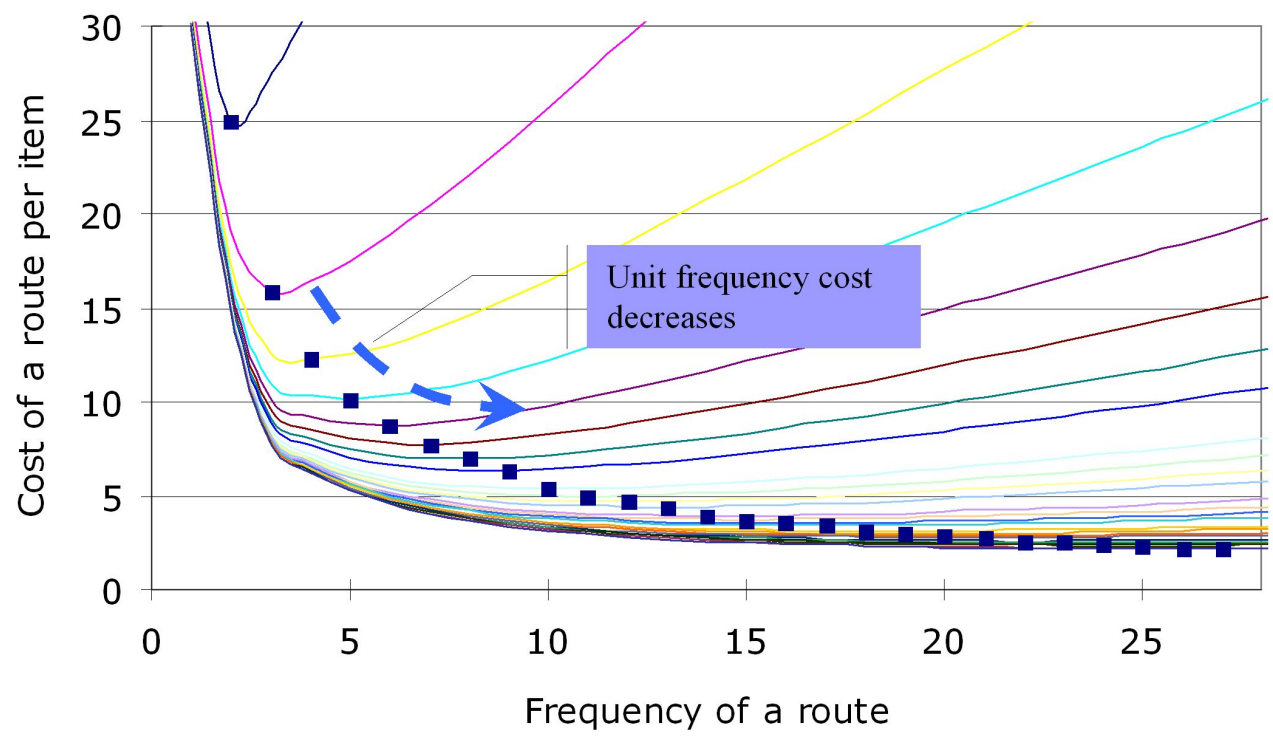

Figure 4.

Change in average cost, $C_{r} / Q_{r}$, according to frequency 


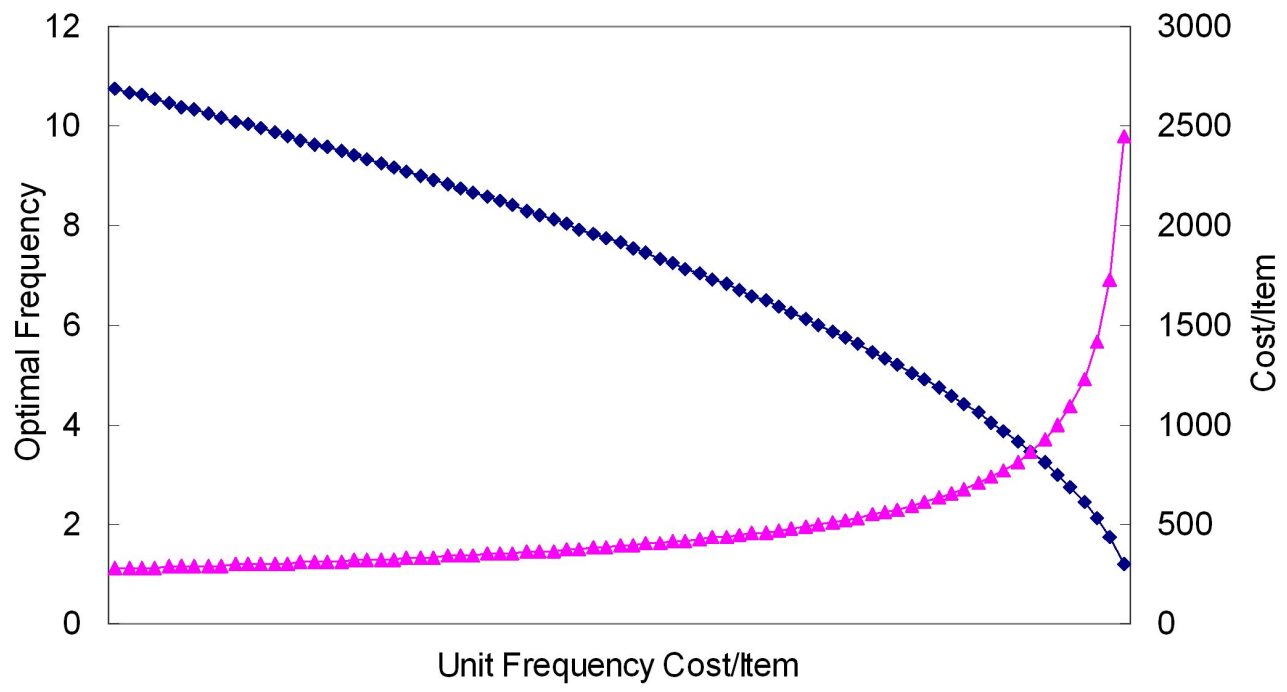

\section{$\rightarrow$ Optimal Frequency $\leadsto$ - Minimum Cost/tem}

Figure 5.

Optimal frequency and the minimum average cost during unconstrained conditions

We first consider the maximum and minimum constraints for the frequencies. The minimum frequency, $f_{r}^{\mathrm{min}}$, is determined by the train capacity and the amount of items being shipped. The minimum frequency of a route $r$ can be calculated as Equation [10].

$f_{r}^{\mathrm{min}}=\left\lceil\frac{Q_{r}}{k_{r}^{\mathrm{max}}}\right\rceil$

On the other hand, the maximum constraints for the frequency, $f_{r}^{\max }$ is influenced by the fleet size and the cycle time of the route. $\mathrm{T} \Delta C_{r}=\left[A_{r}+t p \cdot\{\}\right]$ he cycle time of a route consists of the travel time and the stopping time during a trip.. The maximum frequency of a route $r$ is expressed as Equation [11].

$$
f_{r}^{\max }=\left\lfloor\frac{s_{r}}{\text { cycletime }_{r}}\right\rfloor=\left\lfloor\frac{s_{r}}{\left\{\left(D_{r} / v_{r}\right)+t^{s t} \cdot L_{r}\right\}}\right\rfloor
$$


Now, we will focus on the integral property of the frequency. If the optimal frequency in Equation [7], $\left\lfloor\left(f_{r}\right)_{u}\right\rfloor$ or $\left\lceil\left(f_{r}\right)_{u}\right\rceil$ in order to minimize the cost of the route $r$. The difference between total costs according to the two integers, $\triangle C_{r}$ are calculated as follows.

$$
\begin{aligned}
\Delta C_{r}= & {\left[A_{r}+t p \cdot\left\{\left(c^{t r} \cdot D_{r}+c^{s t} \cdot L_{r}\right) \cdot\left\lfloor\left(f_{r}\right)_{u}\right\rfloor+\frac{t v \cdot Q_{r}}{\left.\left.2\left[\left(f_{r}\right)_{u}\right]\right\}\right]}\right.\right.} \\
& -\left[A_{r}+t p \cdot\left\{\left(c^{t r} \cdot D_{r}+c^{s t} \cdot L_{r}\right) \cdot\left\lceil\left(f_{r}\right)_{u}\right]+\frac{t v \cdot Q_{r}}{\left.\left.2\left[\left(f_{r}\right)_{u}\right]\right\}\right]}\right.\right. \\
= & t p \cdot \frac{\left(\left\lceil\left(f_{r}\right)_{u}\right]-\left\lfloor\left(f_{r}\right)_{u}\right\rfloor\right)}{2\left[\left(f_{r}\right)_{u}\right\rceil\left\lfloor\left(f_{r}\right)_{u}\right\rfloor}\left[t v \cdot Q_{r}-2\left(c^{t r} \cdot D_{r}+c^{s t} \cdot L_{r}\right) \cdot\left\lceil\left(f_{r}\right)_{u}\right\rceil\left\lfloor\left(f_{r}\right)_{u}\right\rfloor\right] \\
= & t p \cdot \frac{\left(\left\lceil\left(f_{r}\right)_{u}\right]-\left\lfloor\left(f_{r}\right)_{u}\right\rfloor\right)}{\left\lceil\left(f_{r}\right)_{u}\right\rceil\left\lfloor\left(f_{r}\right)_{u}\right\rfloor}\left(c^{t r} \cdot D_{r}+c^{s t} \cdot L_{r}\right)\left[\frac{t v \cdot Q_{r}}{\left.2\left(c^{t r} \cdot D_{r}+c^{s t} \cdot L_{r}\right)^{-} \cdot\left\lceil\left(f_{r}\right)_{u}\right\rceil\left\lfloor\left(f_{r}\right)_{u}\right\rfloor\right]}\right. \\
= & t p \cdot \frac{\left(\left\lceil\left(f_{r}\right)_{u}\right]-\left\lfloor\left(f_{r}\right)_{u}\right\rfloor\right)}{\left\lceil\left(f_{r}\right)_{u}\right\rceil\left\lfloor\left(f_{r}\right)_{u}\right\rfloor}\left(c^{t r} \cdot D_{r}+c^{s t} \cdot L_{r}\right)\left[\left\{\left(f_{r}\right)_{u}\right\}^{2}-\cdot\left\lceil\left(f_{r}\right)_{u}\right\rceil\left\lfloor\left(f_{r}\right)_{u}\right\rfloor\right]
\end{aligned}
$$

In Equation [16], the difference between two integers, $\left\lceil\left(f_{r}^{*}\right)_{u}\right\rceil-\left\lfloor\left(f_{r}^{*}\right)_{u}\right\rfloor$, have the value of either 0 or 1 . If $\left(f_{r}\right)_{u}$ is an integer, $\left\lfloor\left(f_{r}\right)_{u}\right\rfloor$ is equal to $\left\lceil\left(f_{r}\right)_{u}\right\rceil\left(\Delta C_{r}=0\right)$, and then we can choose either one of them. If it is not an integer,

we should check the sign of $\triangle C_{r}$. Using Equation [7], we choose $\left\lfloor\left(f_{r}\right)_{u}\right\rfloor$ if the product of $\left\lceil\left(f_{r}\right)_{u}\right\rceil$ and $\left\lfloor\left(f_{r}\right)_{u}\right\rfloor$ are equal to or larger than the square of the optimal frequency in an unconstrained condition, $\left(f_{r}\right)_{u}\left(\Delta C_{r} \leq 0\right)$. Otherwise we choose $\left\lceil\left(f_{r}\right)_{u}\right\rceil$. The optimal integer value of the frequency which minimizes the total cost can be expressed as follows.

$$
f_{r}^{*}= \begin{cases}\left\lfloor\left(f_{r}\right)_{u}\right\rfloor & \text { if }\left(f_{r}\right)_{u} \leq C_{I}, \\ \left\lceil\left(f_{r}\right)_{u}\right\rceil & \text { otherwise. }\end{cases}
$$

where,

$$
\begin{aligned}
& \left(f_{r}\right)_{u}=\sqrt{\frac{t v \cdot Q_{r}}{2\left\{c^{t r} \cdot D_{r}+c^{s t} \cdot L_{r}\right\}}} \\
& C_{I}=\sqrt{\left[\left(f_{r}\right)_{u}\right\rceil\left[\left(f_{r}\right)_{u}\right\rfloor}
\end{aligned}
$$


Equation [13] can solve the optimal frequency independently of whether $\left(f_{r}\right)_{u}$ is an integer or not. Therefore, the optimal frequency and the minimum total cost of a route $r$ in a constrained condition can be calculated as follows.

$$
\begin{aligned}
& C_{r}^{*}=A_{r}+\left\{c^{t r} \cdot D_{r}+c^{s t} \cdot L_{r}\right\} \cdot f_{r}^{*}+\frac{t v \cdot Q_{r}}{2 f_{r}^{*}} \\
& f_{r}^{*}=\left\{\begin{array}{llrl}
f_{r}^{\min } & \text { if } & \left(f_{r}\right)_{u} \leq f_{r}^{\min } \\
\left\lfloor\left(f_{r}\right)_{u}\right\rfloor & \text { if } & f_{r}^{\min }<\left(f_{r}\right)_{u} \leq \min \left[C_{I}, f_{r}^{\max }\right] \\
\left\lceil\left(f_{r}\right)_{u}\right] & \text { if } \max \left[C_{I}, f_{r}^{\min }\right]<\left(f_{r}\right)_{u} \leq f_{r}^{\max } \\
f_{r}^{\max } & \text { if } & \left(f_{r}\right)_{u}>f_{r}^{\max }
\end{array}\right.
\end{aligned}
$$

where

$$
\begin{array}{ll}
\left(f_{r}\right)_{u}=\sqrt{\frac{t v \cdot Q_{r}}{2\left\{c^{t r} \cdot D_{r}+c^{s t} \cdot L_{r}\right\}}} & C_{I}=\sqrt{\left(\mid\left(f_{r}\right)_{u} \|\left[\left(f_{r}\right)_{u}\right\rfloor\right)} \\
f_{r}^{\min }=\left\lceil\frac{Q_{r}}{k_{r}^{\text {max }}}\right\rceil & f_{r}^{\max }=\left\lfloor\frac{s_{r}}{\left\{\left(D_{r} / v_{r}\right)+t^{s t} \cdot L_{r}\right\}}\right\rfloor
\end{array}
$$

Figure 6 shows the optimal frequency and minimum cost of a route $r$ according to the unit frequency cost per item in a constrained condition. The minimum cost in a constrained condition is larger than it is in an unconstrained condition as in the following cases: i) the optimal frequency in an unconstrained condition is smaller than the minimum frequency, which depends on the trains capacity and the amount of items, as in case 1) in Figure 6. Then, $f_{r}^{*}=f_{r}^{\mathrm{min}}$; ii) the optimal frequency in an unconstrained condition is not a integer value as in cases 2) or 3) in Figure 6. Then, $f_{r}^{*}=\left\lfloor\left(f_{r}\right)_{u}\right\rfloor$ or $\left\lceil\left(f_{r}\right)_{u}\right\rceil$; iii)the optimal frequency in an unconstrained condition is larger than the maximum frequency, which is determined by the fleet size and the cycle time of the route, as in case 4) in Figure 6. Then, $f_{r}^{*}=f_{r}^{\max }$. It should also be noted that the difference in minimum costs between a constrained and an unconstrained condition is negligible unless the unit frequency cost per item is relatively high. The situation which we are considering in this paper is that the items are shipped by trains from a port to their destinations and that the unit frequency cost per item is therefore relatively smaller than that of the other modes. These results show that the optimal frequency in an unconstrained condition can be used without considering the 
integral property in low-cost transportation systems. On the other hand, it should be noted that the minimum frequency constraints are one of the most important influences on the optimum.

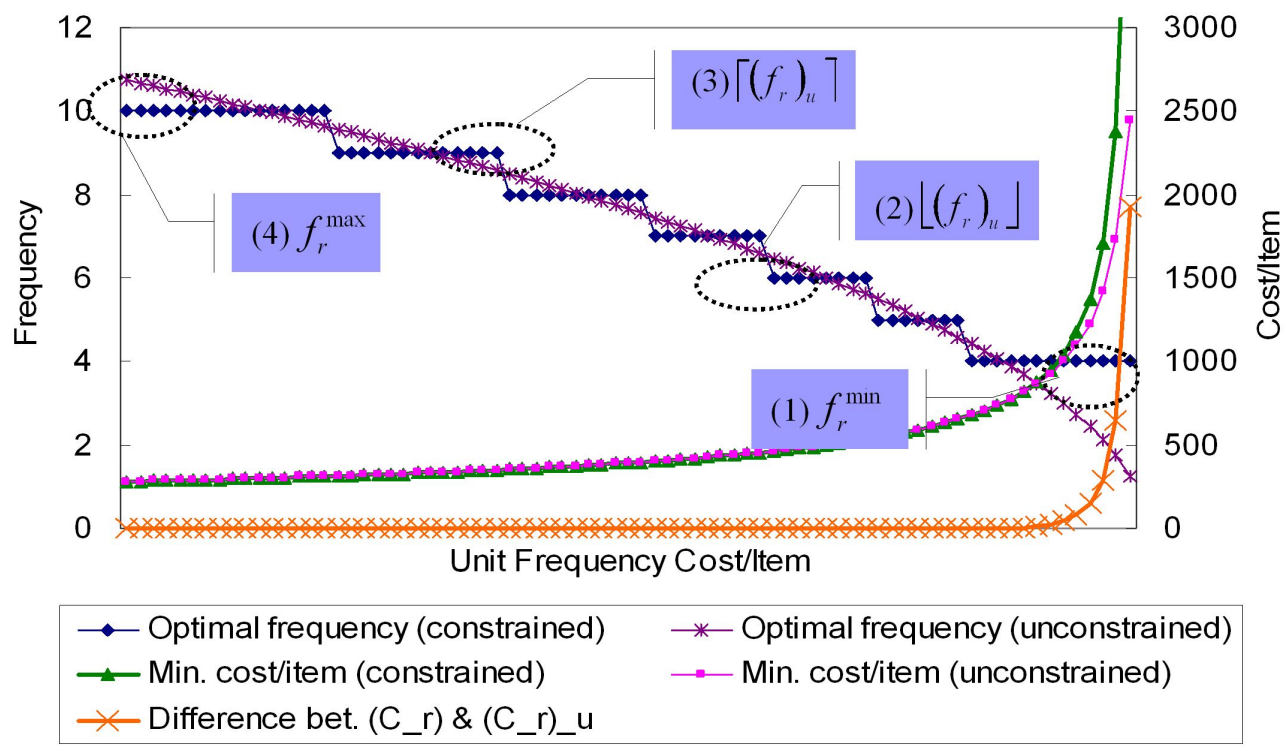

Figure 6.

Optimal frequency and minimum average cost under constrained conditions

\subsection{Decision of Optimal Fleet Size}

In Equation [15], the optimal frequency of a route is restricted by its maximum value, which is influenced by its fleet size. The optimal fleet size of each route $r, s_{r}^{*}$ can be calculated as follows if we don't consider the total fleet size constraint, $\sum_{r}^{R} S_{r}^{*} \leq S$.

$$
s_{r}^{*}=\left\lceil f_{r}^{*} \times \text { cycle time }_{r}\right\rceil=\left\lceil f_{r}^{*} \cdot\left\{\frac{D_{r}}{v_{r}^{\omega}}+t^{s} \cdot\left(1+L_{r}\right)\right\}\right\rceil
$$

If the summation of the optimal fleet size over all routes $r,(r=1,2, \ldots . \mathrm{R})$ is equal to or smaller than the total fleet size $S$, we can accept the current solution as being optimum. Otherwise, we should decrease the frequencies of some routes in order to satisfy the total 
fleet size constraint. We are introducing the following rules in order to choose the route of the frequency which will be reduced (see Figure 7).

- We cannot reduce the frequency of route $r$ of which $f_{r}^{*}$ is equal to its minimum frequency, $f_{r}^{\mathrm{min}}$ (Case 1 in Figure 7).

- We can reduce the frequency of route $r$ of which $f_{r}^{*}$ is equal to or smaller than $\left(f_{r}^{\mathrm{max}}-1\right)$ without any increase in the cost (Case 2 in Figure 7).

- We can also reduce the frequency of route $r$ of which $f_{r}^{*}$ is equal to $f_{r}^{\mathrm{max}}$ at the expense of additional costs (Case 3 in Figure 7).

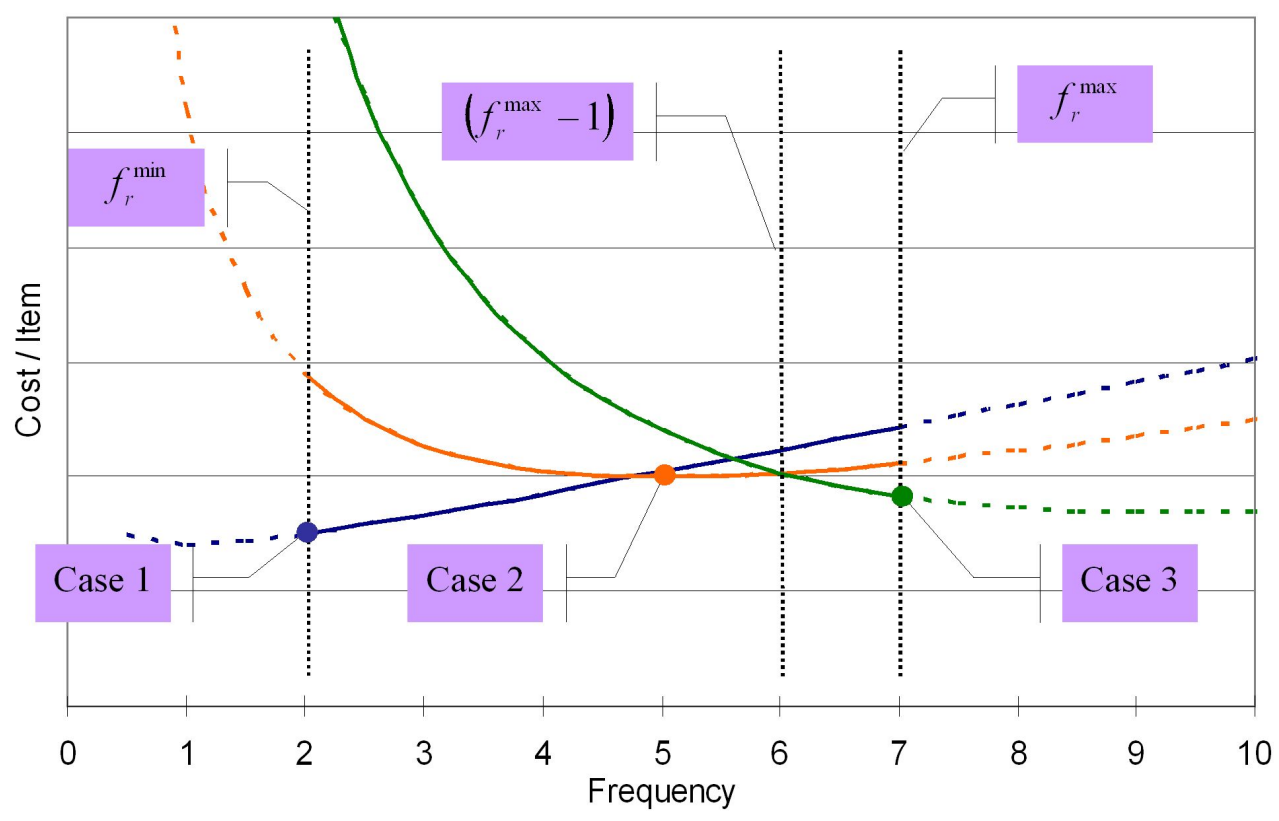

Figure 7.

Selection rules for routes with reduced frequency

After reducing the frequencies of some routes which are influenced by the second rule, we have to calculate the change in the minimum cost of route $r, \delta C_{r}$ according to the change in its maximum frequency, $f_{r}^{\mathrm{max}}$ in the third rule, if the summation of the optimal fleet size is still larger than the total fleet size. $\delta C_{r}$ can then be calculated as follows. 


$$
\begin{aligned}
\delta C_{r}= & {\left[A_{r}+\left(c^{t r} \cdot D_{r}+c^{s t} \cdot L_{r}\right) \cdot\left(f_{r}^{*}-1\right)+\frac{t v \cdot Q_{r}}{2\left(f_{r}^{*}-1\right)}\right] } \\
& -\left[A_{r}+\left(c^{t r} \cdot D_{r}+c^{s t} \cdot L_{r}\right) \cdot\left(f_{r}^{*}\right)+\frac{t v \cdot Q_{r}}{\left(f_{r}^{*}\right)}\right] \\
= & \frac{1}{2\left(f_{r}^{*}\right)\left(f_{r}^{*}-1\right)}\left[t v \cdot Q_{r}-2\left(c^{t r} \cdot D_{r}+c^{s t} \cdot L_{r}\right) \cdot\left(f_{r}^{*}\right)\left(f_{r}^{*}-1\right)\right]
\end{aligned}
$$

After calculating and comparing the overall routes which were influenced by the third rule, we selected a route $r$ where $\delta C_{r}$ is the minimum, and decreased its optimal frequency $f_{r}^{*}$ by 1 . We iterate this procedure until the summation of the optimal fleet size is equal to or smaller than the total fleet size $S$. The Solution procedure in this study is illustrated in Figure 8. 


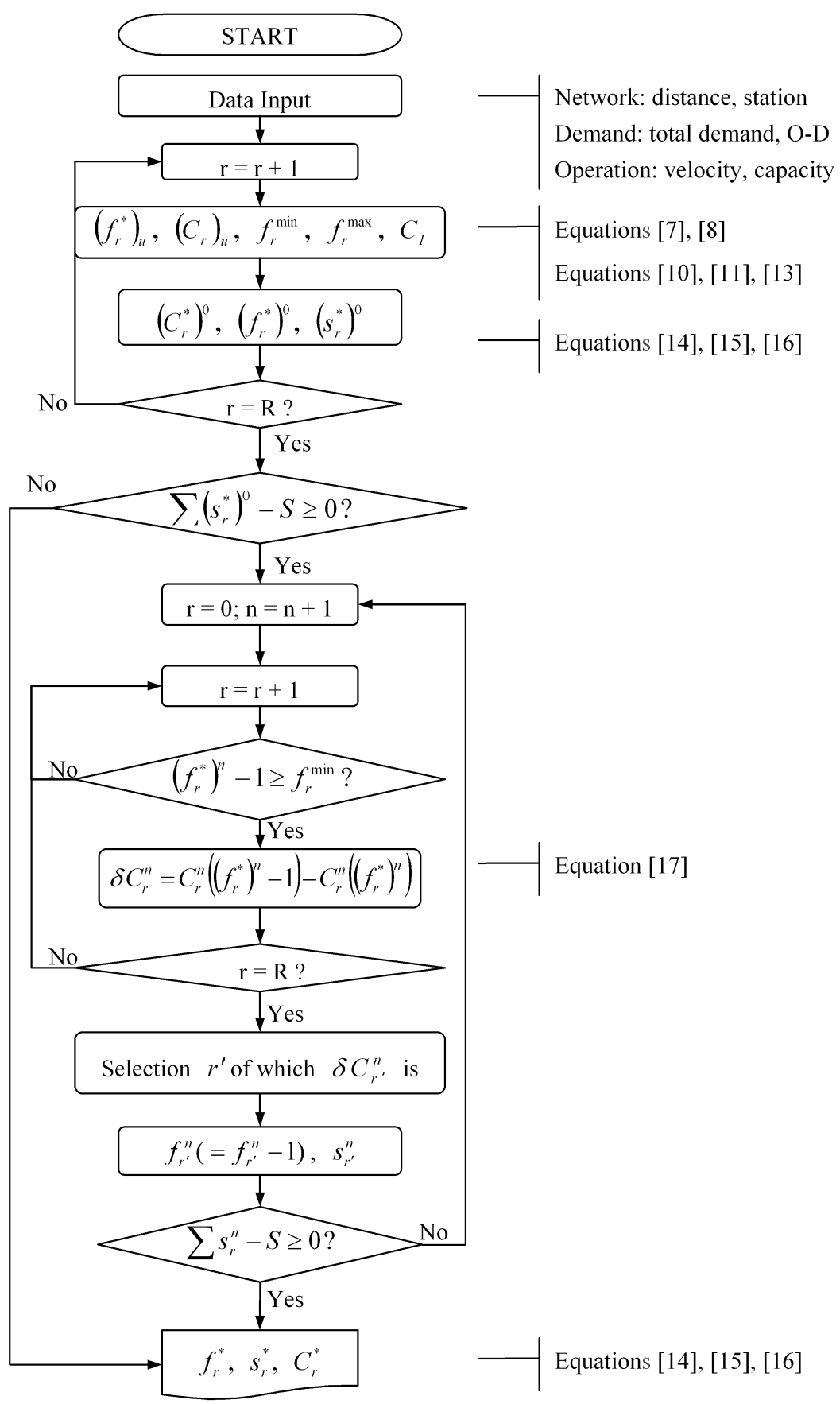

Figure 8.

Solution procedure 


\section{Empirical Analysis}

\subsection{Data}

In this section, the empirical analysis on the developed model is shown based on the real data which was provided by the Korea Transport DataBase (KTDB) (http://www.ktdb.go.kr) .In this study, we selecte dsixrail ways from amongall of the routes taking into consideration the length of the overlapping sections and the properties of the network and demand. The available data were daily demands in 2004 and the loading and unloading patterns of items during different time periods were generated based on a field survey. The unit costs and default values from the empirical studies are summarized in Table 2.

\section{Table 2.}

Unit costs and default values from the empirical studies

\begin{tabular}{|c|c|c|c|c|c|c|c|}
\hline \multicolumn{2}{|c|}{ Routes } & R01 & R02 & R03 & R04 & R05 & R06 \\
\hline \multicolumn{2}{|c|}{ \# of stations } & 3 & 4 & 4 & 5 & 6 & 2 \\
\hline \multicolumn{2}{|c|}{ Distance $(\mathrm{km})$} & 15.7 & 21.3 & 12.4 & 20.5 & 31.2 & 17.5 \\
\hline Symbol & \multicolumn{2}{|c|}{ Unit } & Value & Symbol & \multicolumn{2}{|c|}{ Unit } & Value \\
\hline$c^{t r}$ & \multicolumn{2}{|c|}{ [\$/frequency-km] } & 36.89 & $t v$ & \multicolumn{2}{|c|}{ [\$/item-hr] } & 13.6 \\
\hline$c^{s t}$ & \multicolumn{2}{|c|}{$[\$ /$ stop $]$} & 4.89 & $v_{r}$ & \multicolumn{2}{|c|}{$[\mathrm{km} / \mathrm{hr}]$} & 40 \\
\hline$t^{s t}$ & \multicolumn{2}{|l|}{$[\mathrm{hr}]$} & 0.25 & $k_{r}^{\max }$ & \multicolumn{2}{|c|}{ [item/train] } & 600 \\
\hline
\end{tabular}

\subsection{Results}

The results of the empirical studies are presented in Table 3, Table 4 and Table 5. Table 3 shows the optimal solutions for real data under the constraint that the total fleet size is 30. The frequencies for R04 and R05 in the unconstrained condition were the minimum frequencies of their routes, respectively. The greatest increase in cost occurred on the R02 while the greatest decrease in frequency occurred on the R03 in comparison to the unconstrained condition.

Table 4 and Table 5 show the effects of the change in demand and time value, 
respectively. Table 4 shows that the optimal frequencies in the unconstrained condition were the same as those in Table 5, while those in the constrained condition increased in spite of the increase in demand. The frequencies of all routes were optimized at their minimum frequencies and the results of Table 5 indicate the effects of change in time value. According to the increase in time value from 13.6 to 40.3 , both frequencies and fleet sizes should be increased. This result shows that the investment in the purchase of trains can cut down on expenses for logistics and inventories.

\section{Table 3.}

Optimal solutions for real dat $1 \mathrm{a}(\mathrm{S}=30)$

\begin{tabular}{c|r|r|r|r|r|r}
\hline \multirow{2}{*}{ Route } & \multicolumn{3}{|c|}{ Unconstrained } & \multicolumn{3}{|c}{ Constrained $(S=30)$} \\
\cline { 2 - 7 } & Frequency & Fleet size & \multicolumn{1}{c|}{ Cost } & Frequency & Fleet size & \multicolumn{1}{c}{ Cost } \\
\hline \hline R01 & 4 & 5 & 4,918 & 3 & 4 & 5,056 \\
\hline R02 & 3 & 5 & 5,169 & 2 & 4 & 5,565 \\
\hline R03 & 6 & 8 & 5,620 & 4 & 6 & 5,870 \\
\hline R04 & 3 & 6 & 5,117 & 3 & 6 & 5,117 \\
\hline R05 & 3 & 7 & 6,890 & 3 & 7 & 6,890 \\
\hline R06 & 4 & 4 & 5,113 & 3 & 3 & 5,172 \\
\hline Total & 23 & 35 & 32,828 & 18 & 30 & 33,670 \\
\hline
\end{tabular}

\section{Table 4.}

Optimal solutions for $30 \%$ increased demand $(\mathrm{S}=32)$

\begin{tabular}{c|r|r|r|r|r|r}
\hline \multirow{2}{*}{ Route } & \multicolumn{4}{|c|}{ Unconstrained } & \multicolumn{3}{|c}{ Constrained $(S=32)$} \\
\cline { 2 - 7 } & Frequency & Fleet size & \multicolumn{1}{c}{ Cost } & Frequency & Fleet size & \multicolumn{1}{c}{ Cost } \\
\hline \hline R01 & 4 & 5 & 5,576 & 3 & 4 & 5,933 \\
\hline R02 & 3 & 5 & 5,889 & 3 & 5 & 5,889 \\
\hline R03 & 6 & 8 & 6,343 & 5 & 7 & 6,492 \\
\hline R04 & 3 & 6 & 5,845 & 3 & 6 & 5,845 \\
\hline R05 & 3 & 7 & 7,789 & 3 & 7 & 7,789 \\
\hline R06 & 4 & 4 & 5,756 & 3 & 3 & 6,290 \\
\hline Total & 23 & 35 & 37,199 & 20 & 32 & 37,977 \\
\hline
\end{tabular}




\section{Table 5.}

Optimal solutions for high value-added Items $(\mathrm{S}=35$, time value=40.3)

\begin{tabular}{c|r|r|r|r|r|r}
\hline \multirow{2}{*}{ Route } & \multicolumn{3}{|c|}{ Unconstrained } & \multicolumn{3}{c}{ Constrained $(S=35)$} \\
\cline { 2 - 7 } & Frequency & \multicolumn{1}{|c|}{ Fleet size } & \multicolumn{1}{c|}{ Cost } & Frequency & \multicolumn{1}{c}{ Fleet size } & \multicolumn{1}{c}{ Cost } \\
\hline \hline R01 & 7 & 8 & 8,220 & 4 & 5 & 9,224 \\
\hline R02 & 5 & 8 & 8,648 & 3 & 5 & 9,886 \\
\hline R03 & 9 & 12 & 9,401 & 5 & 7 & 11,299 \\
\hline R04 & 5 & 9 & 8,566 & 3 & 6 & 9,879 \\
\hline R05 & 5 & 12 & 11,583 & 3 & 7 & 12,777 \\
\hline R06 & 6 & 6 & 8,514 & 4 & 4 & 9,319 \\
\hline Total & 37 & 55 & 54,932 & 22 & 34 & 62,383 \\
\hline
\end{tabular}

\section{Conclusions}

Frequency and fleet size are the most important decision variables which have an influence on the efficiency of freight transportation systems. It is of interest to railway operators, therefore, to improve the efficiency of the system by optimizing the fleet size and frequency for each route. This paper proposes a model which determines the optimal frequency of each route under the total fleet size constraint from a single origin to many destinations. The tradeoff between transportation and inventory costs determine the optimal frequency under the total fleet size and the capacity constraints.

The model that we developed in this paper is expected to contribute significantly to several decisions which must be made by transit operators, such as the allocation of additional fleet size, the determination of flexible frequency corresponding with time-variable demand, and the acquisition of additional trains. The model developed in this paper is expected to provide more reliable and realistic results as well as providing more precise parameter estimations.

Some issues not addressed in this paper deserve further research. Various operational alternatives should be investigated in order to improve the efficiency of freight systems, such as vehicle mixing and skip-stop scheduling.

\section{Acknowledgements}

This work was partially supported by INHA UNIVERSITY Research Grant and the National Research Foundation of Korea Grant funded by The Korean Government (NRF-2011-413-B00008). 


\section{References}

Assad, A. A. (1980) Modelling of Rail Networks: Toward a Routing/Makeup Model. Transportation Research Part B: Methodological, Vol. 14, No. 1-2, pp. 101-114.

Blumenfeld, D. E., L. D. Burns, J. D. Diltz, and C. F. Daganzo (1985) Analyzing Trade-offs between Transportation, Inventory and Production Costs on Freight Networks. Transportation Research Part B: Methodological, Vol. 19, No. 5, pp. 361-380.

Choong, S. T., M. H. Cole, and E. Kutanoglu (2002) Empty Container Management for Intermodal Transportation Networks. Transportation Research Part E: Logistics and Transportation Review, Vol. 38, No. 6, pp. 423-438.

Constantin, I., and M. Florian (1995) Optimizing Frequencies in a Transit Network: a Nonlinear Bi-level Programming Approach. International Transactions in Operational Research, Vol. 2, No. 2, pp. 149-164.

Crainic, T. G., J.-A. Ferland, and J.-M. Rousseau (1984) A Tactical Planning Model for Rail Freight Transportation. Transportation Science, Vol. 18, No. 2, pp. 165-184.

Daganzo, C. F. (2005) Logistics Systems Analysis. Springer-Verlag, New York.

dell'Olio, L., J. L. Moura, and A. Ibeas (2006) Bi-Level Mathematical Programming Model for Locating Bus Stops and Optimizing Frequencies. In Transportation Research Record: Journal of Transportation Research Board, No. 1971, TRB, National Research Council, Washington, D.C., pp. 23-31.

Eilon, S., C. D. T. Watson-Gandy, and N. Christofides (1971) Distribution Management: Mathematical Modelling and Practical Analysis. Griffin, London.

Francis, P., K. Smilowitz, and M. Tzur (2006) The Period Vehicle Routing Problem with Service Choice. Transportation Science, Vol. 40, No. 4, pp. 439-454.

Furth, p. G., and A. B. Rahbee (2000) Optimal Bus Stop Spacing Through Dynamic Programming and Geographic Modeling. In Transportation Research Record: Journal of Transportation Research Board, No. 1731, TRB, National Research Council, Washington, D.C., pp. 15-22.

Groothedde, B., C. Ruijgrok, and L. Tavasszy (2005) Towards Collaborative, Intermodal Hub Networks: A Case Study in the Fast Moving Consumer Goods Market. Transportation Research Part E: Logistics and Transportation Review, Vol. 41, No. 6, pp. 567-583.

Hall, R. W. (1993) Design for Local Area Freight Networks. Transportation Research Part B: Methodological, Vol. 27, No. 2, pp. 79-95. 
Janic, M. (2007). Modelling the Full Costs of an Intermodal and Road Freight Transport Network. Transportation Research Part D: Transport and Environment, Vol. 12, No. 1, pp. 33-44.

Marín, A., and J. Salmerón (1996) Tactical Design of Rail Freight Networks. Part I: Exact and Heuristic Methods. European Journal of Operational Research, Vol. 90, No. 1, pp. 26-44.

Newman, A. M. and C. A. Yano (2000) Scheduling Direct and Indirect Trains and Containers in an Intermodal Setting. Transportation Science, Vol. 34, No. 3, pp. 256-270.

O'Kelly, M. E., and D. L. Bryan (1998) Hub Location with Flow Economies of Scale. Transportation Research Part B: Methodological, Vol. 32, No. 8, pp. 605-616.

Saka, A. A. (2001) Model for Determining Optimum Bus-Stop Spacing in Urban Areas. Journal of Transportation Engineering, Vol. 127, No. 3, pp. 195-199.

van Oudheusden, D. L., and W. Zhu (1995) Trip Frequency Scheduling for Bus Route Management in Bangkok. European Journal of Operational Research, Vol. 83, No. 3, pp. 439-451. 